\title{
Akut dekompanse KY ile hastaneye yatan olgularda sakubitril/valsartan başlanabilir mi?
}

\author{
Dr. Yüksel Çavuşoğlu \\ Eskişehir Osmangazi Üniversitesi Tıp Fakültesi, Kardiyoloji Anabilim Dalı, Eskişehir
}

Akut dekompanse kalp yetersizliğinde (ADKY) hastane içi mortalite \%4-6 civarındadır. Hastane sonrası özellikle ilk 3 ayda mortalite yüksek kalmaya devam etmekte (\%4-6), daha sonra 6. aya kadar giderek azalmakta ve $\% 2$ 'ler düzeyine inmektedir. ${ }^{[1]}$ Söz konusu 6 aylık dönemde gerçekleşen ölümlerin büyük bölümü KY'ye bağlı ölümler şeklinde gerçekleşmektedir. Benzer şekilde hastane sonrası gerçekleşen rehospitalizasyonların yaklaşık yarısı ilk 2 ay içinde ortaya çıkmaktadır. ${ }^{[2]}$ Dolayısı ile ADKY'de hem hastane içi hem de hastane sonrası ilk 3-6 ayda mortalite ve KY rehospitalizasyon açısından çok hassas bir dönemden geçilmektedir. Bu nedenle söz konusu hassas dönemde kanıta dayalı etkin KY tedavisinin optimal düzeyde uygulanması büyük önem taşımaktadır.

Sakubitril/valsartan, kronik stabil düşük ejeksiyon fraksiyonlu KY'de (DEF-KY) enalaprile göre çok daha güçlü mortalite ve morbidite yararı sağladığı kanıtlanmış bir ilaçtır. Bu nedenle günümüz modern KY tedavisinde yer verilmesi gereken bir medikasyon olarak gösterilir. Ancak yakın zamana kadar ADKY olgularının tedavisinde ki rolü konusunda yeterli veri bulunmamakta idi. Bununla beraber PARADIGM HF analizleri, enalapril ile karşılaştırldığında Sakubitril/ valsartan'in hastane sonrasi KY hospitalizasyonu ilk 30 günde anlamlı farklılaştıracak şekilde azalttığını göstermekte idi ${ }^{[3]}$ Her ne kadar ADKY olgularında da etkinliğinin üstünlüğü konusunda bir şüphe olmasa da güvenliğine ilişkin verisinin bulunmaması nedeniyle ADKY olgularında kullanımına ilişkin öneri bulunmamaktaydı. Yakın zamanda sonuçları yayınlanan TRANSITION ve PIONEER HF çalışmaları sakubitril/valsartanın ADKY hastalarının tedavisindeki yerini netleştirdi.

TRANSITION çalışması, ADKY nedeniyle hastaneye yatırılan DEF-KY olgularda klinik stabilizasyon sonrası hastane içinde ve hastaneden taburcu olduktan sonra başlanan sakubitril/valsartanın güvenlik ve tolerabilitesini test etmeyi amaçlayan bir çalışma idi. ${ }^{[4]}$ Ülkemizin de yer aldığı çalışmaya ADKY ile hastaneye yatan, tedavi sonrası klinik olarak stabil olan, NYHA II-IV, EF $\leq \% 40$, son 24 saat içinde IV medikasyonları kesilmiş ve sistolik kan basıncı son altı saattir $\geq 110 \mathrm{mmHg}$ olan 1002 olgu alındı. Randomizasyon ile hastaların bir bölümüne hastaneden çıkmadan önce diğer bölümüne hastaneden taburcu olduktan sonra $2 \times 50$ veya $2 \times 100 \mathrm{mg}$ sakubitril/valsartan başlandı ve 2 haftada bir doz arttırılarak $2 \times 200$ mg hedef doza uptitre edildi. Çalışmanın önemli özelliklerinden biri çalışmaya dahil edilen hastaların \%24'ünün ACEİ/ARB naif hastalarından oluşmasıyd1. Ayrıca olguların \%29'u de novo (ilk defa ortaya çıkan) ADKY olgusuydu. Çalışmanın primer sonlanım noktası olan 10. haftada hedef doza ulaşan olgu oranı açısından 2 grup arasında anlamlı fark bulunmadı (\%45 ve \%50.4, $\mathrm{p}=0.092)$. Sekonder sonlanım noktaları olan 10 . haftada $2 \times 100$ veya $2 \times 200 \mathrm{mg}$ doza ulaşan olgu oranı (\%62.5 ve \%68, $\mathrm{p}=0.071)$ ve 10 . haftada herhangi bir dozda sakubitril/valsartan dozunu en az 2 hafta boyunca tolere etmiş olgu oranı (\%86.4 ve \%88.8, p=0.262) açısından da bir fark yoktu. Söz konusu sonlanım noktaları açısında ACEİ/ARB naif hastalarla, ACEİ/ARB kullanmakta olan hastalar arasında da anlamlı fark bulunmadı. Güvenlik açısından merak edilen hipotansiyon (\%11), hiperkalemi (\%11) ve renal fonksiyonlarda bozulma (\%4) oranları PARADIGM HF'deki oranlara benzer bulundu. Ayrica hem hastane içinde hem de hastane sonrası sakubitril/ valsartan başlanan olgu gruplarında NTproBNP düzeylerinin ilaç başlandıktan sonra 15 gün içinde anlamlı düştüğü saptandı.

PIONEER HF çalışması da ADKY nedeniyle hastaneye yatırılan DEF-KY olgularında kinik stabilizasyon sonrası başlanan sakubitril/valsartanın, enalapril ile karşılaştırıldı ğında güvenlik, tolerabilite ve NTproBNP üzerine etkisini test etmeyi amaç- 
Tablo 1. Akut dekompanse KY olgularında sakubitril/valsartan ile yapılan klinik çalışmalar

\begin{tabular}{|c|c|c|}
\hline Çalışma & PIONEER-HF & TRANSITION \\
\hline Hasta Sayısı, n & 887 & 1002 \\
\hline Çalışma İlacı & $\mathrm{S} / \mathrm{V}$ vs enalapril & Taburcu öncesi ve sonrası S/V \\
\hline Tedavi süresi & 8 hafta & 10 hafta \\
\hline ACE-i/ARB naif olgu, n (\%) & $459(\% 52)$ & $242(\% 24)$ \\
\hline De novo AKY, n (\%) & $303(\% 34)$ & $286(\% 29)$ \\
\hline Primer sonlanım & $\begin{array}{l}\text { 1. haftanın sonunda NT-proBNP S/N } \\
\text { ile enalaprile göre anlamlı azaldı }\end{array}$ & $\begin{array}{l}\text { Taburculuk öncesi ve sonrası gruplarda } \\
\text { 10. haftada hedef doza ulaşma oranı } \\
\text { benzer bulundu }\end{array}$ \\
\hline $\begin{array}{l}\text { Güvenlik ile ilgili } \\
\text { sonlanım noktaları }\end{array}$ & $\begin{array}{l}\text { Hipotansiyon, hiperkalemi, renal kötüleşme } \\
\text { S/V ve enalapril gruplarında benzer }\end{array}$ & $\begin{array}{l}\text { Hipotansiyon, hiperkalemi, renal kötüleşme } \\
\text { taburcu öncesi ve sonrası S/V gruplarında benzer }\end{array}$ \\
\hline $\begin{array}{l}\text { ACEI/ARB naif olgularda } \\
\text { primer sonlanımlar }\end{array}$ & $\begin{array}{l}\text { 1. haftanın sonunda NT-proBNP düşüşü } \\
\text { ACEI/ARB naif ve naif olmayan } \\
\text { olgularda benzer }\end{array}$ & $\begin{array}{l}\text { 10. haftada hedef doza ulaşma oranı } \\
\text { ACEI/ARB naif ve naif olmayan olgularda benzer }\end{array}$ \\
\hline
\end{tabular}

layan bir çalışma idi. ${ }^{[5]}$ Çalışmaya $\mathrm{EF} \leq \% 40$, son 6 saat içinde IV medikasyonları kesilmiş, NTproBNP $\geq 1600 \mathrm{pg} / \mathrm{mL}$ veya $\mathrm{BNP} \geq 400 \mathrm{pg} / \mathrm{mL}$ ve sistolik kan basinc1 son 6 saattir $\geq 100 \mathrm{mmHg}$ olan 881 olgu alındı. Randomizasyon ile hastaların bir bölümüne sakubitiril/valsartan (hedef doz 2x200 mg) diğer bölümüne enalapril (hedef doz 2x10 mg) verildi. Çalışmaya alınan olguların \%52'si ACEİ/ARB naif ve \%34'ü de novo ADKY olgulardan oluşmaktayd. Çalışma süresi 8 hafta olarak belirlendi. Çalışmanın primer sonlanım noktası olan NTproBNP düşüşünün sakubitril/valsartan grubunda enalapril grubuna göre anlamlı olarak daha fazla gerçekleştiği gözlendi $(\mathrm{p}<0.001)$. Söz konusu NTproBNP düşüşünün ilk 1 hafta içinde enalaprile göre anlamlı düşüş göstermesi sakubitril/valsartanının nörohormonal etkinliğinin ne kadar erken ortaya çıktığını göstermesi açısından dikkat çekici idi. Sakubitril/valsartan ile enapril arasında güvenlik sonlanım noktaları olan semptomatik hipotansiyon (\%15 ve \%12.7), hiperkalemi ( $\geq 5.5$ $\mathrm{mEq} / \mathrm{L})(\% 11.6$ ve \%9.3), renal fonksiyonlarda kötüleşme (\%13.6 ve \%14.7) ve anjiyoödem görülme oranları (\%0.2 ve \%1.4) açısından bir fark yoktu ve PARADIGM HF ile TRANSITION'da gözlenen oranlara benzer oranlar söz konusuydu. KY nedeniyle tekrar hastaneye yatış sakubitril/valsartan kolunda enalapril koluna göre daha az gerçekleşti (\%8 ve \%13.8, $\mathrm{p}=0.005)$. NTproBNP'de ki anlamlı düşüş ACEI/ARB naif olgularda, ACEİ/ARB kullanım öyküsü olan olgularla benzerdi.

TRANSITION ve PIONEER HF çalışmalarının sonuçları sakubitril/valsartan'ın klinik uygulamada kullanımıyla ilgili yeni kazanımlar sağlamıştır (Tablo 1). Bunlardan en önemlisi, ADKY nedeniyle hastaneye yatırılan DEF-KY olgularında, hastaneden çıkmadan önce ancak klinik stabilizasyon sağlandıktan sonra sakubitril/valsartanın güvenle başlanabileceğinin gösterilmesidir. Ayrıca bu çalışmalar, ACEİ/ARB naif hastalarda da sakubitril/valsartan başlanmasının güvenli ve etkin olduğunu ortaya koymuştur. Tüm bunlara ilave olarak erken dönemde sakubitril/valsartan başlanmasının enalaprile göre daha iyi bir nörohormonal yanıt oluşturduğu ve haftalar içinde de olsa klinik yarar sağladığı gösterilmiştir.

Nitekim 2019 yılı içinde yayınlanan ESC-HFA'nın KY tedavisi ile ilgili fikir birliği raporunda, ${ }^{[6]}$ sakubitril/valsartan'1n ACEİ/ARB naif hastalarda dahil olmak üzere ADKY ile hastaneye yatırılan olgularda klinik stabilizasyon sonrası güvenle başlanabileceği, bu olgularda natriüretik peptid yükseklliği şartının aranmasına gerek olmadığ 1 ve erken dönemde başlanmasının bu hasta grubunda klinik yarar sağladığına ilişkin yeterli kanıtlarında bulunduğu vurgulanmıştır.

\section{Kaynaklar}

1. Solomon SD, Dobson J, Pocock S, Skali H, McMurray JJ, Granger $\mathrm{CB}$, et als. Influence of nonfatal hospitalization for heart failure on subsequent mortality in patients with chronic heart failure. Circulation 2007;116:1482-7.

2. Gheorghiade M, Vaduganathan M, Fonarow GC, Bonow RO. Rehospitalization for heart failure: problems and perspectives. J Am Coll Cardiol 2013;61:391-403.

3. Packer M, McMurray JJ, Desai AS, Gong J, Lefkowitz MP, Rizkala $\mathrm{AR}$, et al. Angiotensin receptor neprilysin inhibition compared with enalapril on the risk of clinical progression in surviving patients with heart failure. Circulation 2015;131:54-61. 
4. Wachter R, Senni M, Belohlavek J, Straburzynska-Migaj E, Witte KK, Kobalava Z, et al. Initiation of sacubitril/valsartan in haemodynamically stabilised heart failure patients in hospital or early after discharge: primary results of the randomised TRANSITION study. Eur J Heart Fail 2019;21:998-1007.

5. Velazquez EJ, Morrow DA, DeVore AD et al. Angiotensin-neprilysin inhibition in acute decompensated heart failure. $\mathrm{N}$ Engl J Med
2019;380:539-48.

6. Seferovic PM, Ponikowski P, Anker SD, Bauersachs J, Chioncel O, Cleland JGF, et al. Clinical practice update on heart failure 2019: pharmacotherapy, procedures, devices and patient management. An expert consensus meeting report of the Heart Failure Association of the European Society of Cardiology. Eur J Heart Fail 2019;21:116986. 